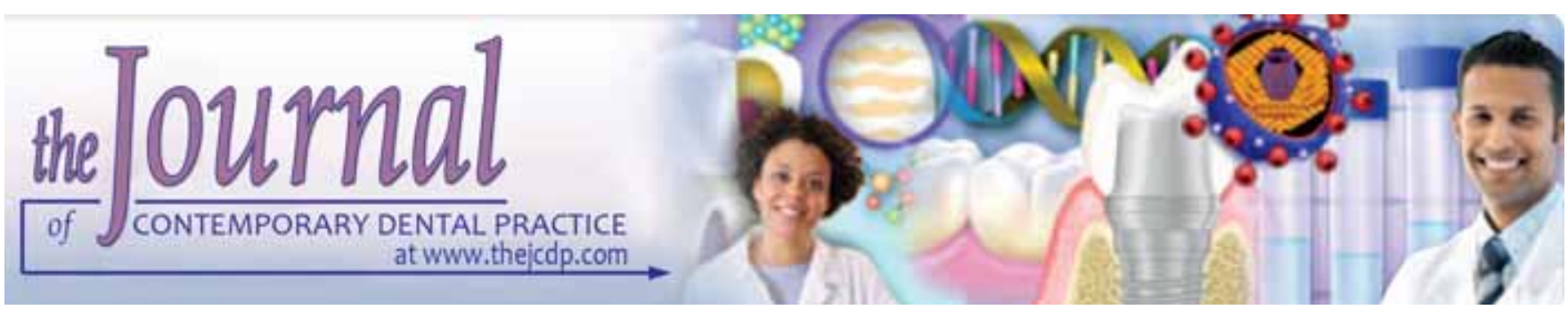

\title{
pH-changes during Intracoronal Bleaching: An in vivo Study
}

\author{
Daphne Câmara Barcellos, Alessandra Buhler Borges, Regina Célia dos Santos Pinto Silva \\ Luciana Maria Ribeiro, Cesar Rogério Pucci, Carlos Rocha Gomes Torres
}

\begin{abstract}
Objectives: This study aimed to measure $\mathrm{pH}$ changes during 14 days intracoronal bleaching with hydrogen peroxide/sodium perborate and carbamide peroxide/sodium perborate.
\end{abstract}

Materials and methods: Twenty patients presenting endodontically treated central maxillary incisors with color alterations were divided in two groups $(n=10)$ : Group CP + SP: $37 \%$ carbamide peroxide + sodium perborate paste; Group HP + SP: $30 \%$ hydrogen peroxide + sodium perborate paste. The $\mathrm{pH}$ values were measured using a digital microprocessor at different times: Baseline, 2, 7 and 14 days. Data were analyzed with two-way ANOVA followed by Tukey's test $(\alpha=0.05)$.

Results: ANOVA showed $p<0.00$ which indicated significant difference between the groups. The mean values ( $\pm \mathrm{sd})$ and the results of the Tukey's test were: HP + SP/14 days-7.98 $( \pm 0.58) \mathrm{a} ; \mathrm{HP}+\mathrm{SP} / 7$ days-8.59 $( \pm 0.18) \mathrm{b} ; \mathrm{HP}+\mathrm{SP} / 2$ days$8.83( \pm 0.32) \mathrm{bc} ; \mathrm{HP}+\mathrm{SP} /$ Baseline-8.83 $( \pm 0.01) \mathrm{bc} ; \mathrm{CP}+\mathrm{SP} /$ Baseline-8.89 ( \pm 0.01$) b c ; C P+S P / 14$ days-9.11 $( \pm 0.58) c d$; $\mathrm{CP}+\mathrm{SP} / 7$ days $-9.54( \pm 0.16) \mathrm{de} ; \mathrm{CP}+\mathrm{SP} / 2$ days $-9.66( \pm 0.08)$ de. The group HP + SP resulted in significantly lower $\mathrm{pH}$ values compared with group $\mathrm{CP}+\mathrm{SP}$.

Conclusion: It can be concluded that both associations showed alkaline $\mathrm{pH}$ values; however, there was significant reduction in the $\mathrm{pH}$ values of the $30 \%$ hydrogen peroxide associated with sodium perborate after 14 days.

Clinical Significance: The association of hydrogen peroxide and carbamide peroxide with sodium perborate paste presented alkaline characteristics during the 14-day evaluated period. Thus, regarding $\mathrm{pH}$ changes, both associations can be considered safe as intracoronal bleaching agents.

Keywords: Bleaching agents, Peroxides, Intracoronal, pH.

How to cite this article: Barcellos DC, Borges AB, Silva RCDSP, Ribeiro LM, Pucci CR, Torres CRG. pH-changes during Intracoronal Bleaching: An in vivo Study. J Contemp Dent Pract 2011;12(2):109-113.

Source of support: Nil

Conflict of interest: None declared

\section{INTRODUCTION}

In 1976, Nutting and Poe ${ }^{1}$ introduced the 'walking bleach' intracoronal bleaching technique and used to regain the natural color of dental crown. This technique combine sodium perborate and hydrogen peroxide (concentrations of 30-35\%) which is inserted into the pulp chamber. More recently, carbamide peroxide (concentration of 37\%) has also been used in the 'walking bleach' intracoronal bleaching technique showing good results. ${ }^{2}$

However, these bleaching agents can cause adverse effects, among them external cervical root resorption and superficial structural changes in dentin. ${ }^{3,4}$ External cervical root resorption may occur due to inflammatory reaction caused by internal bleaching procedure. ${ }^{5,6}$ The $\mathrm{pH}$ decrease caused by bleaching agents at the periodontal tissue ${ }^{7}$ can stimulate osteoclastic activity resulting in bone resorption. ${ }^{8}$ Additionally, peroxides might change the organic and inorganic compounds of dentin tissue ${ }^{9,6}$ and can generate denaturation of dentin proteins, which induces a foreign body reaction. ${ }^{6,10}$ Some authors state that $\mathrm{pH}$ variation of the bleaching agents can cause this denaturation., ${ }^{6,11-13}$

When a bleaching agent is inserted into the pulp chamber, oxidation reactions initiate resulting in variation of $\mathrm{pH}$ solution. ${ }^{14}$ However, most studies have been carried in vitro, ${ }^{7,8,15}$ and it is difficult to consider the real change of $\mathrm{pH}$ values that occur in vivo. Due to the occurrence of side effects associated to $\mathrm{pH}$ decrease of bleaching agents inside pulp chamber and because the available data on the $\mathrm{pH}$ values of bleaching agents were conflicting and the need of in vivo studies, the purpose of this study was to measure, in vivo, the $\mathrm{pH}$ values of the materials commonly used for bleaching pulpless teeth (walking bleach technique) at different time intervals after application. The null hypothesis investigated was that both bleaching agents present no $\mathrm{pH}$ change during the study period.

\section{MATERIALS AND METHODS}

This study was submitted and approved by the Research Ethics Committee of São José dos Campos School of 
Dentistry, for research involving human beings.Patients were selected from a triage at the Department of Restorative Dentistry, from São José dos Campos School of Dentistry UNESP. Twenty patients, age range 18 to 55 years, were chosen. The subjects had central maxillary incisors endodontically treated with discolorations. The cause of tooth discoloration was determined by medical history, and a radiograph was made to check the quality of the root filling. ${ }^{16,17}$

Patients with the following characteristics were included: no caries in the discolored tooth; medical history of trauma to dental tissue; no gingival inflammation; adequate quality of the root filling; normal width of the periodontal ligament space and no history of previous intracoronary bleaching.

All subjects signed a treatment terms agreement with the risks involved during the bleaching procedure. ${ }^{17}$ Two calibrated professionals (postgraduate students) performed the bleaching procedures.

A rubber dam was applied before performing the access. The pulp chamber was opened with spherical diamond bur and cleansed with sodium hypochlorite. The endodontic filling was reduced $3 \mathrm{~mm}$ below the cementoenamel junction with Gates-Glidden burs. ${ }^{17}$ The root filling was sealed with a layer of $2 \mathrm{~mm}$ of light-cured glass ionomer cement (Vitremer, 3M ESPE, St Paul, MN, USA) and light cured using a halogen light curing unit (Curing Light XL 3000, 3M Dental Products, St Paul, MN, USA), with an output intensity of over $500 \mathrm{~mW} / \mathrm{cm}^{2}$, according to the manufacturer's instruction. Patients were divided into two groups $(n=10)$, according to the bleaching agent used.

Group CP + SP: 2 g sodium perborate-tetrahydrate (Whiteness Perborato, FGM, Joinville, SC, Brazil) per $1 \mathrm{~mL}$ of $37 \%$ carbamide peroxide solution (Whiteness Super, FGM, Joinville, SC, Brazil); group HP + SP: 2 g sodium perborate-tetrahydrate (Whiteness Perborato, Joinville, SC, Brazil) per $1 \mathrm{~mL}$ of $30 \%$ hydrogen peroxide solution (Peróxidos do Brasil Ltda, São Paulo, SP, Brazil).

The same calibrated postgraduate student mixed the paste with standard viscosity (respecting the powder/liquid or gel ratio) for all the patients treated. ${ }^{17}$ Each mixture was weighed in a balance (Mettler Toledo AB204, Alameda Araguaia, São Paulo, Brazil) and diluted in distilled water at a rate of $87.5 \mathrm{mg} / \mathrm{mL}$, then a sample was separated. The $\mathrm{pH}$ values of each sample of the mixtures were recorded using a digital microprocessor Hanna model HI 9224 (Hanna Instruments, Woonsocket, RI, USA), fitted with a glass microelectrode with a combined $\mathrm{pH}$ probe (Ingold, Switzerland) calibrated with buffers of pH 7.0 and 9.0.

The bleaching mixture was inserted in the pulp chamber. A small sterile cotton pellet was placed on the bleaching agent and the temporary filling ${ }^{17}$ was done with self-etching adhesive system (One Up Bond F Plus, Tokuyama Dental
Co.) and photocured composite (TPH, Dentsply De Trey D GmbH, Konstanz, Germany).

After the periods (2, 7 and 14 days), the pulp chamber was carefully opened, and a sample of the mixture was collected for each period. The samples were collected at the same (standardized) location in the pulp chamber to avoid $\mathrm{pH}$ variation at different locations. The $\mathrm{pH}$ values were recorded following the same protocols described previously. The $\mathrm{pH}$ values were recorded at baseline and after 2, 7 and 14 days respectively.

Bleaching sessions were performed regularly once in 2 weeks until the color appeared to be stable. However, no measurement of $\mathrm{pH}$ values has been performed again. After the last bleaching session, a calcium hydroxide/propylene glycol paste was placed in the pulp cavity for 15 days to neutralize the bleaching agents' products. ${ }^{17}$ The final restoration was made with photocured composite (TPH, Dentsply).

The data were submitted to the two-way ANOVA (time of measurement and bleaching agent) and the Tukey's test. The level of significance adopted was 5\%.

\section{RESULTS}

The ANOVA results for the interaction between factors (bleaching agent and time of measurement) showed $p=0.0000(F=10.53)$ with 3 degree of freedom, which resulted in significant differences among groups.

Table 1 shows the results of Tukey's test for interaction between bleaching agent and time of measurement. The group HP + SP showed significantly lower $\mathrm{pH}$ values than the group $\mathrm{CP}+\mathrm{SP}$. The group $\mathrm{HP}+\mathrm{SP} / 14$ days showed $\mathrm{pH}$ values significantly lower than all other groups and the groups $\mathrm{CP}+\mathrm{SP} / 7$ days and $\mathrm{CP}+\mathrm{SP} / 2$ days showed the highest $\mathrm{pH}$ values.

Graph 1 shows the behavior of $\mathrm{pH}$ value means for bleaching agents in different periods of measurement.

Table 1: Results of Tukey's test for interaction between bleaching agent and time of measurement

\begin{tabular}{llllllll}
\hline $\begin{array}{l}\text { Bleaching } \\
\text { agent }\end{array}$ & Time & Mean $( \pm S D)$ & & Homogeneous sets* \\
& & & & & & \\
$\mathrm{HP}+\mathrm{SP}$ & 14 days & $7.98( \pm 0.58)$ & $\mathrm{A}$ & & & & \\
$\mathrm{HP}+\mathrm{SP}$ & 7 days & $8.59( \pm 0.18)$ & & $\mathrm{B}$ & & & \\
$\mathrm{HP}+\mathrm{SP}$ & 2 days & $8.83( \pm 0.32)$ & $\mathrm{B}$ & $\mathrm{C}$ & & \\
$\mathrm{HP}+\mathrm{SP}$ & Baseline & $8.83( \pm 0.01)$ & $\mathrm{B}$ & $\mathrm{C}$ & & \\
$\mathrm{CP}+\mathrm{SP}$ & Baseline & $8.89( \pm 0.01)$ & $\mathrm{B}$ & $\mathrm{C}$ & & \\
$\mathrm{CP}+\mathrm{SP}$ & 14 days & $9.11( \pm 0.58)$ & & & C & D & \\
$\mathrm{CP}+\mathrm{SP}$ & 7 days & $9.54( \pm 0.16)$ & & & & D & E \\
$\mathrm{CP}+\mathrm{SP}$ & 2 days & $9.66( \pm 0.08)$ & & & & D & E
\end{tabular}

*Means accompanied by the same letters presented no statistically significant differences (HP + SP-30\% hydrogen peroxide + sodium perborate-tetrahydrate; $\mathrm{CP}+\mathrm{SP}-37 \%$ carbamide peroxide + sodium perborate-tetrahydrate) 


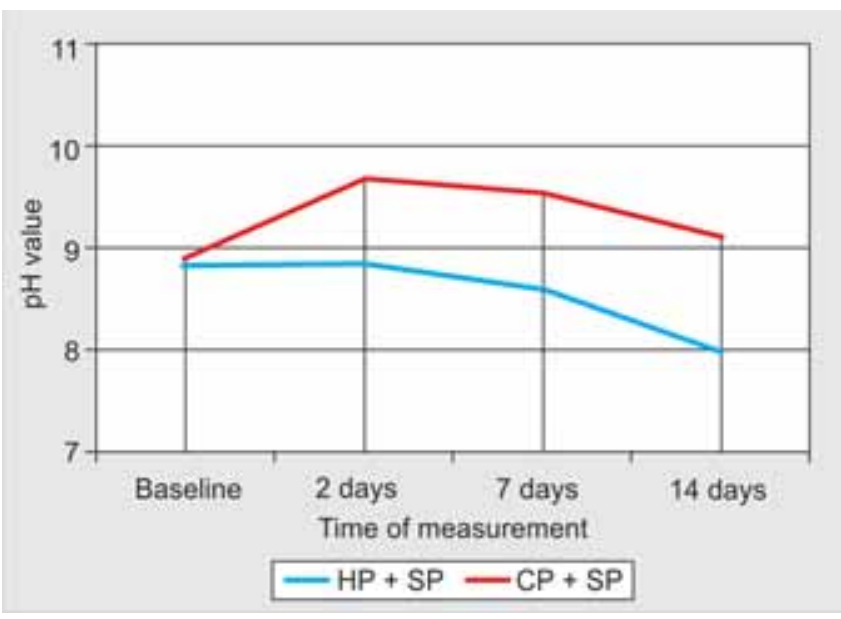

Graph 1: Mean of $\mathrm{pH}$ values for bleaching agents according to the time of measurement. (HP $+\mathrm{SP}-30 \%$ hydrogen peroxide + sodium perborate-tetrahydrate; $\mathrm{CP}+\mathrm{SP}-37 \%$ carbamide peroxide + sodium perborate-tetrahydrate)

\section{DISCUSSION}

Sodium perborate contains about 95\% perborate and 9.9\% avaliable oxygen. ${ }^{18,19}$ When sodium perborate contacts moisture, it decomposes in hydrogen peroxide and sodium metaborate. Sodium metaborate is alkaline and raises the $\mathrm{pH}$ of bleaching solution. Carbamide peroxide decomposes into $6.4 \%$ urea and $3.6 \%$ hydrogen peroxide when in contact with tooth structure. ${ }^{18}$ The byproduct urea decomposes into $\mathrm{CO}_{2}$ and ammonia, which raises the $\mathrm{pH}$ value of the bleaching agent. ${ }^{19}$ The hydrogen peroxide (30\%) has $\mathrm{pH}$ value around 4.0 (acidic) and decomposes in water and nascent oxygen when in contact with the dental substrate. The nascent oxygen is responsible for bleaching. ${ }^{19}$

Some reports ${ }^{6,20}$ suggest that peroxides can diffuse through the dentinal tubules, reach periodontal ligament and, consequently, bone. ${ }^{6}$ This can cause complications, such as inflammatory reactions, osteoclastic activity, bone, and external cervical root resorptions. ${ }^{6,21,22}$ According to Rostein and Friedman, ${ }^{7}$ one of several etiological factors associated with these complications is the $\mathrm{pH}$ of the bleaching materials; since the low $\mathrm{pH}$ value of 30 to $35 \%$ hydrogen peroxide results in an acidic environment, which is favorable for osteoclastic activity and, consequently, bone resorption., ${ }^{6,23,24}$ Also, bleaching agents can cause superficial structural changes to dentin, ${ }^{25}$ because the low $\mathrm{pH}$ may produce an acid-etch effect on dentin, dissolving the smear layer and increasing diffusion of hydrogen peroxide through dentinal tubules. ${ }^{6,26,27}$

In this study, the null hypothesis was rejected because both bleaching agents showed $\mathrm{pH}$ variation during the study period. The group that associated $37 \%$ carbamide peroxide and sodium perborate showed $\mathrm{pH}$ values statistically higher than the group that associated 30\% hydrogen peroxide and sodium perborate. Confirming the findings of this study, Weiger et $\mathrm{al}^{15}$ stated that the lower the hydrogen peroxide concentration, the higher the initial pH value. Thus, the 37\% carbamide peroxide is equivalent to $12 \%$ hydrogen peroxide and $25 \%$ urea content which significantly reduces the final concentration of the active principle and, consequently, the $\mathrm{pH}$ value. Consequently, this concentration is lower as compared with the group HP + SP which used 30\% hydrogen peroxide. Moreover, the urea decomposes into $\mathrm{CO}_{2}$ and ammonia which raises the $\mathrm{pH}$ value of the bleaching agent. ${ }^{15}$ Therefore, it maintains the $\mathrm{pH}$ value closer to the neutral $\mathrm{pH}$ of 7.0, decreasing the probability of side effects. Also, the byproduct of the sodium perborate decomposition is sodium metaborate which is alkaline and raises the $\mathrm{pH}$ of the bleaching agents. ${ }^{15}$

The group $\mathrm{CP}+\mathrm{SP}$ at 2 and 7 days showed $\mathrm{pH}$ values significantly higher compared with group $\mathrm{CP}+\mathrm{SP}$ at baseline. Perhaps, the lower $\mathrm{pH}$ values measurement at baseline occurred before, and the sodium perborate decomposes into sodium metaborate (alkaline compound), hydrogen peroxide and nascent oxygen. However, there is no significant difference in $\mathrm{pH}$ values at baseline and at 14 days for the group CP + SP. Several studies state that the alkalinity of bleaching agents increases with time, regardless of the diluting agent used, ${ }^{7,8,15}$ contradicting the findings of this study. According to Haywood, ${ }^{9}$ the $\mathrm{pH}$ value of carbamide peroxide is slightly alkaline at baseline, because it will decompose when in contact with the dental substrate. Also, for the first moment, the carbamide peroxide decomposed into hydrogen peroxide (acid) and urea (alkaline) that justify a $\mathrm{pH}$ value of 8.89 at baseline. Over time, the $\mathrm{pH}$ value increase is due to second reaction, in which hydrogen peroxide decomposes into water, oxygen and urea into $\mathrm{CO}_{2}$ and ammonia which is very alkaline. In this study, the $\mathrm{pH}$ values were above 9.0 at 2 and 7 days of measurement.

The group HP + SP, which used 30\% hydrogen peroxide associated to sodium perborate, presented significant lower $\mathrm{pH}$ values at 14 days of measurement. According to Rostein and Friedman, ${ }^{7}$ sodium perborate is alkaline, whereas $30 \%$ hydrogen peroxide is acidic. However, the $\mathrm{pH}$ of the materials when mixed together gradually changed from acidic to alkaline. Also, the $\mathrm{pH}$ value in extraradicular environment increases with bleaching time. ${ }^{8,15,26}$ This result probably is because the peroxide decomposes into oxygen and water. ${ }^{7}$

However, the $\mathrm{pH}$ values at 14 days of measurement showed significant decrease when compared with other times of measurement. Fuss et $\mathrm{al}^{8}$ evaluated the dentinal tubular permeability of bleaching agents and found that the baseline mean $\mathrm{pH}$ value of the medium surrounding the teeth 
with bleaching agents (sodium perborate and hydrogen peroxide $30 \%$ ) was 7.0 , after 1 hour increased to 7.9 , increased to 9.0 after 3 days, however, after 10 days showed a slight drop to the mean 8.3.

Although the bleaching agents showed significant differences between them, all bleaching agents showed $\mathrm{pH}$ values above 7.0 or alkaline characters. Under the aspect that these bleaching agents do not have acidic characteristics, results of the present study are in agreement with the studies reported by Rostein and Friedman, ${ }^{7}$ Fuss et $\mathrm{al}^{8}$ and Wieger et $\mathrm{al}^{15}$ and do not support the theory that bleaching solution probably induce side effects due to an acidic $\mathrm{pH}$ of the bleaching pastes.

Although the null hypothesis was rejected, this in vivo study suggested that the most important result was that both the associations HP/SP and CP/SP showed alkaline characteristics in all evaluated period. So, we can suggest that they can be considered safe to be used as intrapulpal bleaching agents.

However, the permanence time of bleaching agent in the pulp chamber should be controlled, and other in vivo studies should be performed to ensure the $\mathrm{pH}$ variation of bleaching agents over time.

\section{CONCLUSION}

According to results of this in vivo study, it can be concluded that the 30\% hydrogen peroxide associated with sodium perborate-tetrahydrate resulted in significantly lower $\mathrm{pH}$ values when compared with $37 \%$ carbamide peroxide associated with sodium perborate-tetrahydrate. The lowest $\mathrm{pH}$ values were obtained with $30 \%$ hydrogen peroxide associated with sodium perborate-tetrahydrate after 14 days of measurement. However, both associations studied remained alkaline throughout the study period.

\section{REFERENCES}

1. Nutting EB, Poe GS. A new combination for bleaching teeth. Dent Clin Nort Am 1976;10:655-62.

2. Teixeira EC, Hara AT, Serra MC. Use of 37\% carbamide peroxide in the walking bleach technique: A case report. Quintessence Int 2004;35(2):97-102.

3. Kaneko J, Inoue S, Kawakami S, Sano H. Bleaching effect of sodium percarbonate on discolored pulpless teeth in vitro. $\mathrm{J}$ Endod 2000;26(1):25-28.

4. Cvek M, Lindvall AM. External root resorption following bleaching of pulpless teeth with oxygen peroxide. Endod Dent Traumatol 1985;1(2):56-60.

5. Heithersay GS, Dahlstrom SW, Marin PD. Incidence of invasive cervical resorption in bleached root-filled teeth. Aust Dent $J$ 1994;39(2):82-87.

6. Plotino G, Buono L, Grande NM, Pameijer CH, Somma F Nonvital tooth bleaching: A review of the literature and clinical procedures. J Endod 2008;34(4):394-407.
7. Rotstein I, Friedman S. pH variation among materials used for intracoronal bleaching. J Endod 1991;17(8):376-79.

8. Fuss Z, Szajkis S, Tagger M. Tubular permeability to calcium hydroxide and to bleaching agents. J Endod 1989;8(15):362-64.

9. Haywood VB. History, safety and effectiveness of current bleaching techniques and applications of the nightguard vital bleaching techniques. Quintessence Int 1992;23:471-88.

10. Ho S, Goerig AC. An in vitro comparison of different bleaching agents in the discolored tooth. J Endod 1989;15:106-11.

11. Demarco FF, Freitas JM, Siva MP, Justino LM. Microleakage in endodontically treated teeth; influence of calcium hydroxide dressing following bleaching. Int Endod J 2001;34:495-500.

12. Montgomery S. External cervical resorption after bleaching a pulpless tooth. Oral Surg Oral Med Oral Pathol 1984;57:203-06.

13. Gimlin DR, Schindler WG. The management of postbleaching cervical resorption. J Endod 1990;16:292-97.

14. Price RBT, Sedarous M, Hiltz GS. The $\mathrm{pH}$ of tooth whitening products. J Can Dent Assoc 2000;66:421-26.

15. Weiger R, Kuhn A, Löst C. Effect of various types of sodium perborate on the $\mathrm{pH}$ of bleaching agents. J Endod 1993;19(5): 239-41.

16. Amato M, Scaravilli MS, Farella M, Riccitiello F. Bleaching teeth treated endodontically: Long-term evaluation of a case series. J Endod 2006;32(4):376-78.

17. de Souza-Zaroni WC, Lopes EB, Ciccone-Nogueira JC, Silva RC. Clinical comparison between the bleaching efficacy of 37\% peroxide carbamide gel mixed with sodium perborate with established intracoronal bleaching agent. Oral Surg Oral Med Oral Pathol Oral Radiol Endod 2009;107(2):e43-47.

18. Joiner A. The bleaching of teeth: A review of the literature. J Dent 2006;34(7):412-19.

19. Hanosh FN, Hanosh GS. Vital bleaching: A new light-activated hydrogen peroxide system. J Esthet Dent 1992;4:90-95.

20. Harrington GW, Natkin E. External resorption associated with bleaching of pulpless teeth. J Endod 1979;5(11):344-48.

21. Pashley DH, Livingston MJ. Effect of molecular size on permeability coefficients in human dentine. Arch Oral Biol 1978; 23:391-95.

22. Wang JD, Hume WR. Diffusion of hydrogen ion and hydroxyl ion from various sources through dentine. Int Endod 1988; J 21:17-26.

23. Friedman S, Rotstein I, Libfeld H, Stabholz A, Heling I. Incidence of external root resorption and esthetic results in 58 bleached pulpless teeth. Endod Dent Traumatol 1988;4:23-26.

24. Vaes A. On the mechanisms of bone resorption: The action of parathyroid hormone on the excretion and synthesis of lysosomal enzymes and on extracellular release of acid by bone cells. J Cell Biol 1968;39:676-97.

25. Rotstein I, Dankner E, Goldman A, Heling I, Stabholz A, Zalkind M. Histochemical analysis of dental hard tissues following bleaching. J Endod 1996;22:23-26.

26. Lee GP, Lee MY, Lum SOY, Poh RSC, Lim KC. Extraradicular diffusion of hydrogen peroxide and $\mathrm{pH}$ changes associated with intracoronal bleaching of discoloured teeth using different bleaching agents. Int Endod J 2004;37:500-06.

27. Carrasco LD, Froner IC, Corona SA, Pecora JD. Effect of internal bleaching agents on dentinal permeability of nonvital teeth: Quantitative assessment. Dent Traumatol 2003;19:85-89.

\section{ABOUT THE AUTHORS}

\section{Daphne Câmara Barcellos}

Postgraduate Student, São José dos Campos School of Dentistry, São Paulo State University, São Paulo, Brazil 


\section{Alessandra Buhler Borges}

Assistant Professor, Department of Restorative Dentistry, São José dos Campos School of Dentistry, São Paulo State University, São Paulo, Brazil

\section{Regina Célia dos Santos Pinto Silva}

Professor, Department of Restorative Dentistry, São José dos Campos School of Dentistry, São Paulo State University, São Paulo, Brazil

\section{Luciana Maria Ribeiro}

Dental Surgeon and Trainee, Department of Clinical Research Academic Group (Grupo Academico de Pesquisas Clinicas-GAPEC) São José dos Campos School of Dentistry, São Paulo State University São Paulo, Brazil

\section{Cesar Rogério Pucci}

Assistant Professor, Department of Restorative Dentistry, São José dos Campos School of Dentistry, São Paulo State University, São Paulo, Brazil

\section{Carlos Rocha Gomes Torres}

Assistant Professor, Department of Restorative Dentistry, São José dos Campos School of Dentistry, São Paulo State University, São Paulo, Brazil

\section{CORRESPONDING AUTHOR}

Carlos Rocha Gomes Torres, Faculdade de Odontologia de São José dos Campos, Universidade do Estado de São Paulo, Avenida Engenheiro Francisco José Longo, 777, Jardim São Dimas, São José dos Campos, São Paulo, CEP: 12245-000, Brazil, Phone: (12) 39479048, Fax: (12) 39479010, e-mail: carlosrgt@fosjc.unesp.br 